Two satellites that will chase one another around the globe are poised to map the Earth's gravitational field with unprecedented accuracy. Researchers are feeling the pull of the data, says David Adam.

$\mathrm{n}$ an uncertain world, at least the force of gravity seems reliable: apples drop, feathers fall and what goes up must come down. But things are not as clear cut as they seem. Our lumpy Earth is not a perfect sphere, which means that the pull of gravity is stronger in some places than in others you weigh just a little more in the Rocky Mountains than on a ship in the middle of the Indian Ocean. Nor does gravity keep still. Ocean currents, the flow of magma beneath the Earth's crust and the movement of glaciers all redistribute the planet's mass enough to keep the gravity map in flux.

Earth scientists and oceanographers know roughly what the Earth's gravity map looks like. But until now they have only been able to dream about a map accurate and dynamic enough to monitor phenomena such as ocean currents or the melting of polar ice. This dream is about to come true. On 16 March, an international team of scientists aims to launch the Gravity Recovery and Climate Experiment (GRACE) from Russia's Plesetsk rocket facility, 600 kilometres northeast of St Petersburg. Its five-year mission: to produce the most accurate map of Earth's gravity ever made and to reveal how it changes over time.

GRACE's two trapezoidal satellites will follow identical orbits, one some 220 kilometres ahead of the other. Subtle changes in gravity will affect the leading satellite first, pulling it slightly closer to the Earth, for example, and so fractionally away from its trailing partner. On-board microwave range finders will monitor the distance between the two satellites with extreme precision, reporting back to ground stations up to five times a day. Every 30 days, the satellites will have covered enough of the Earth's surface to

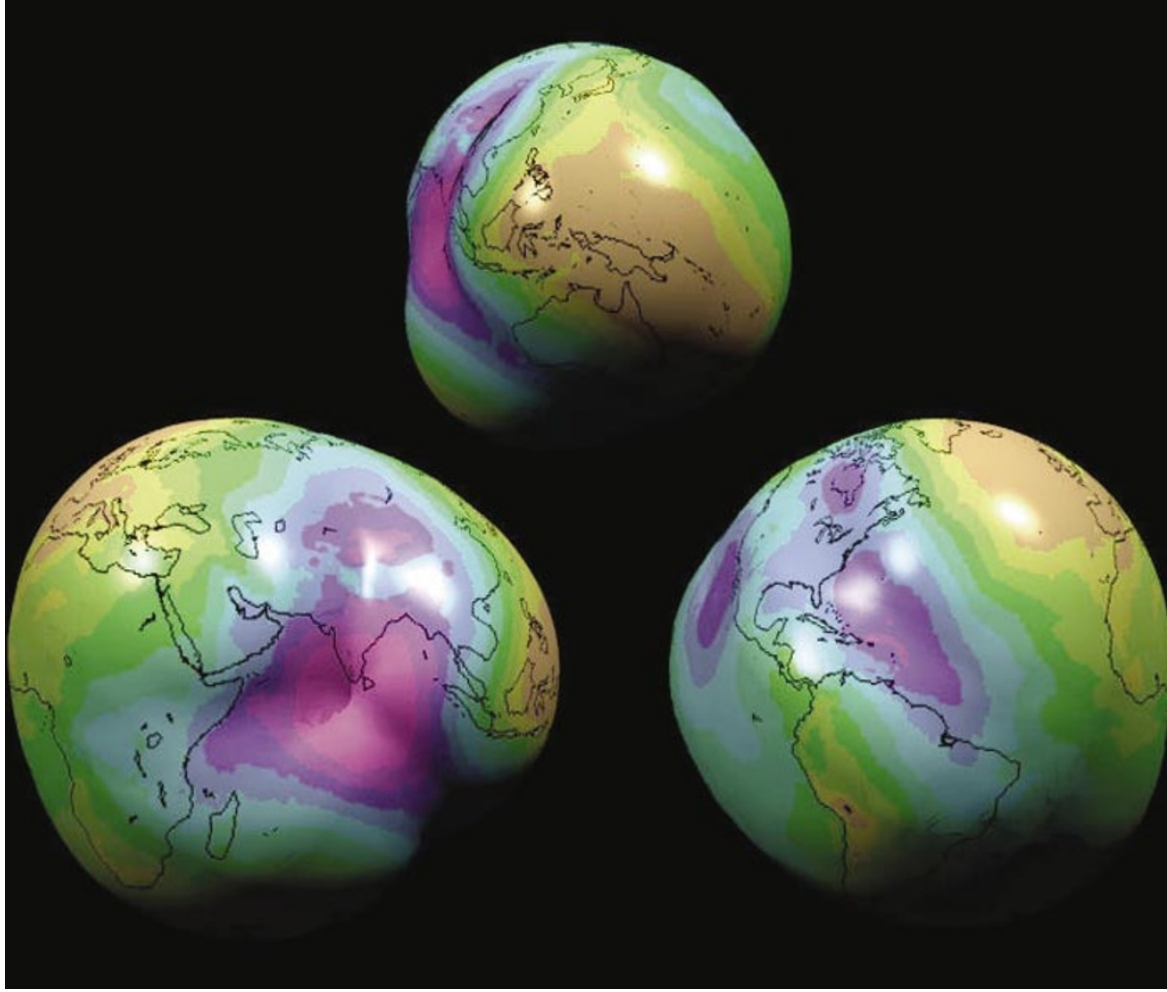

Shaping up: this highly exaggerated 'geoid' shows how the pull of gravity varies across the globe.

construct a complete planetary gravity map.

"Scientists have been talking about and planning a mission like this for a decade or more," says Philip Moore of the University of Newcastle upon Tyne, UK, who specializes in satellite measurements of gravity. "We are fully expecting the results to be quite startling. It could revolutionize many sciences."

\section{Weighty issues}

The US\$150-million mission, a joint project between NASA and the DLR, Germany's aerospace research agency, will reveal new information about the Earth's geology and hydrology. "We'll be able to see various phenomena that involve transporting mass around and how much mass they're actually moving," says Michael Watkins, project scientist for the mission at NASA's Jet

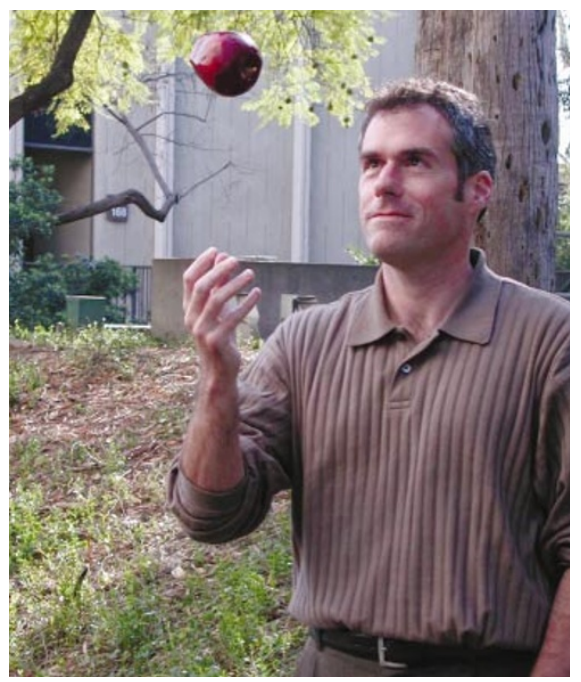

Newton's heir: Michael Watkins is set to measure the force that brings apples down to Earth.
Propulsion Laboratory in Pasadena, California. "These are things that aren't easy to see with any other type of measurement."

Very accurate measurements of gravity in specific places have already been made using gravimeters, sensitive instruments that sense how hard the ground pushes back at them as they are tugged down by gravity. Researchers have produced large-scale maps by combining these ground-based readings with others obtained by tracking the orbital motion of satellites from the ground. In 1999, Germany launched a satellite called CHAMP, which carried Global Positioning System (GPS) equipment to track its position more accurately.

But Watkins says that data from the twin GRACE satellites, which will also carry GPS equipment, will produce a map 100 times more accurate than the best previous effort. The data will be released through free publicaccess websites at NASA and in Germany after six to nine months, says Christoph Reigber of the GFZ, Germany's national Earth-sciences research centre in Potsdam, who heads the German GRACE team.

One way to think of the gravitational variations that GRACE will measure is a representation known as the geoid. This is an imaginary topographical surface where gravity is constant at every point. Sea water piles up over regions of higher gravity, and the geoid is the surface to which the oceans would naturally settle in the absence of wind, tides and currents. A swimmer in the ocean off the southern tip of India, for example, is some 200 metres lower, or closer to the centre of the Earth, than another swimmer near Borneo.

Climate modellers would love to remove the geoid effect from satellite measurements of sea level and so get at the effects of ocean currents and temperature changes. Both are 
more relevant to climate change than the geoid, Watkins says, and a better quantification of the contribution of gravity to these sealevel measurements will allow researchers to eliminate it. "You have to subtract off the geoid to get to that oceanographic part," he says.

Oceanographers such as Philip Woodworth of the Proudman Oceanographic Laboratory near Liverpool, UK, see GRACE as a way to get at deep ocean currents. These currents are part of the global conveyor belt that transports water around the planet, but the ocean depths are inaccessible to standard instruments. Because gravity determines the total mass of water over a particular point on the sea bed, says Woodworth, "it can be used as a surrogate for bottom pressures, which are very important in determining bottom currents". With improved pressure measurements, Woodworth hopes to develop better models of ocean circulation.

\section{Moving pictures}

GRACE could help to improve theories about the fate of the Gulf Stream, which brings warm water across the Atlantic to northwest Europe. Some modellers have suggested that melting Arctic ice could turn off the Gulf Stream and plunge northern Europe into a new ice age. Any weakening of the Gulf Stream over GRACE's five-year lifespan should be evident in its sequence of gravity maps of the North Atlantic.

Indeed, the fact that GRACE's maps will be updated every 30 days is a major advance. "Previously gravity has always been treated as a static quantity, and the attitude has been that we measure it one time and then we're done," says GRACE principal investigator Byron Tapley, an Earth scientist at the University of Texas at Austin's Center for Space Research. "But now static measurements are not enough."

Tapley says that the satellites will be able to pinpoint the gravitational field of areas just a few hundred kilometres across. He expects the measurements to be so accurate that even pro-

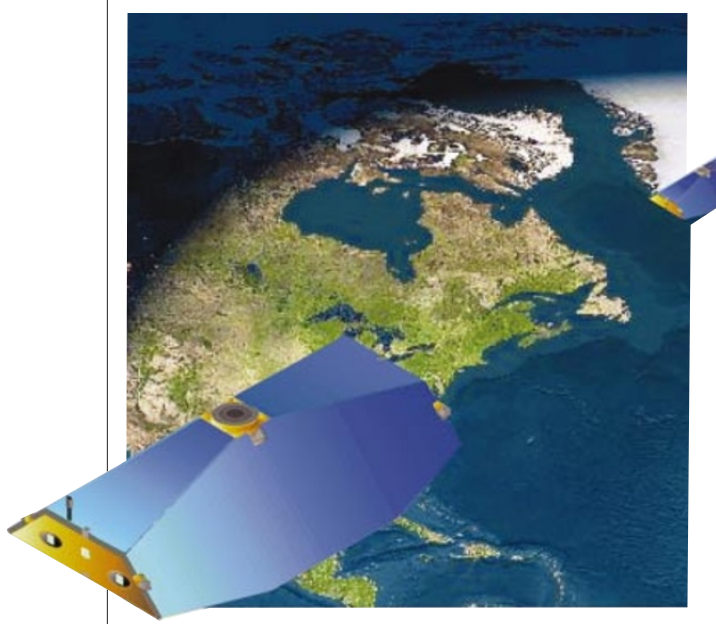

Dynamic duo: the GRACE satellites will supply regularly updated gravity maps.
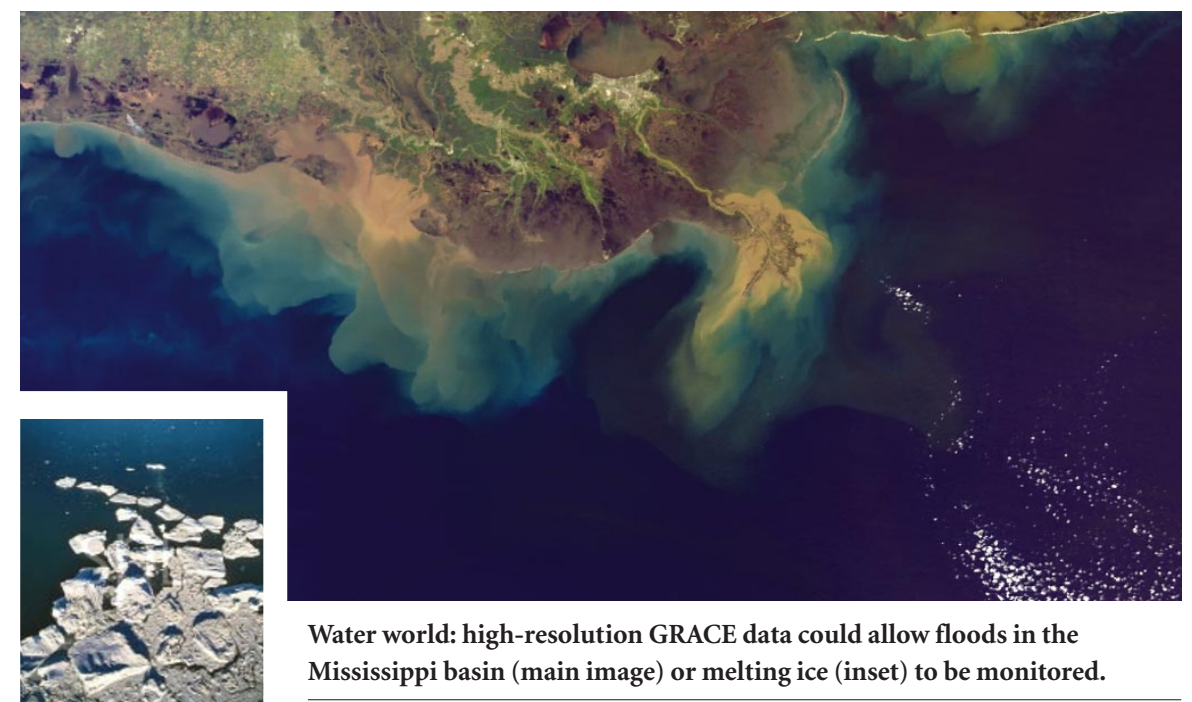

Water world: high-resolution GRACE data could allow floods in the Mississippi basin (main image) or melting ice (inset) to be monitored.

longed periods of heavy rain could turn up in the signal. "If we fly over the Mississippi, Congo or Ganges basins then we may be able to see the effects of major floods," Tapley adds.

This exquisite sensitivity will allow researchers to keep track of all sorts of water movements, from changes in aquifer levels to the melting and freezing of the polar ice caps. Gravity measurements have an advantage over standard measurements of sea level or polar ice volume, in that they can distinguish expansion due to heating from an influx of water, Watkins says. "If you just measure the height of an ocean surface with an altimeter it's hard to separate a change in volume from an increase in mass."

\section{Moisture maps}

GRACE should also help scientists to track global changes in soil moisture, an important factor in the planet's hydrological cycle that influences climate change, erosion, reservoir management, water quality and ecology. Currently, researchers measure soil moisture with remote sensing in some areas, but experts agree that there is a huge need for more global coverage of the sort that GRACE could provide. Other researchers hope that GRACE will reveal density variations within the Earth's mantle, the thick layer of molten rock beneath the crust that is still shrouded in mystery.

But there are limits to GRACE's abilities. Anything that changes or cycles in less than a month, the time that it takes the satellites to complete a single scan, will be impossible to study in detail. Any change in mass smaller than about 2.8 billion tonnes will be invisible. And GRACE picks up an overall gravity signal, which is a composite of the gravitational pull from various features such as water, ice and rocks. The challenge will be to distinguish between the different materials in the signal.

To do this, mission scientists are developing algorithms that will query the data and help them to tell whether a measured shift in

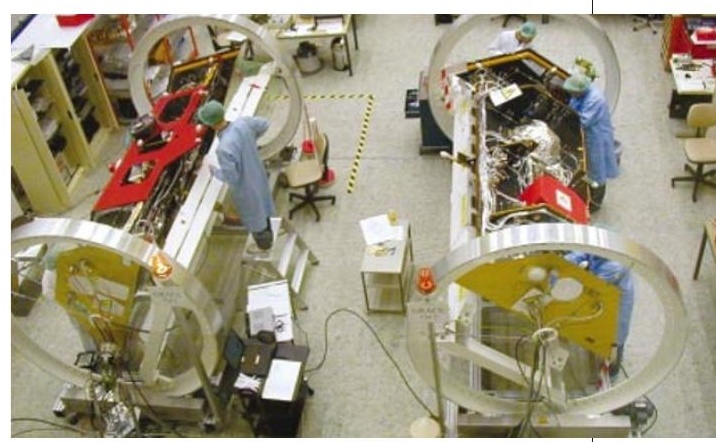

State of GRACE: workers in Plesetsk prepare the twin satellites for their launch later this month.

gravity is caused by swelling water levels in an aquifer or the deeper movement of molten rocks. One factor will be the time-scale involved. Rivers would be expected to produce faster changes than ocean currents, and ocean currents should produce faster changes than deep magma flows. Other information, such as rainfall data, will help to distinguish between different events.

Military scientists are also likely to find applications for the data, Tapley says. For example, accurate measurements of gravity are essential for reliable guidance of longrange missiles. And the oil exploration industry is taking a keen interest, as it believes that precise gravity measurements could help to reveal the locations of untapped oil reserves.

But all good things must come to an end. The satellites will fly at a relatively low altitude of some 500 kilometres for optimal sensitivity. Here they will encounter occasional wisps of atmosphere. The satellites have accelerometers on board to sense any resulting changes in speed and so avoid distorting the data, but their orbit will gradually decay. After about five years, the very force that GRACE was designed to measure will bring the mission to a close, when the Earth's pull finally causes the satellites to burn up in the atmosphere.

David Adam is a news and features writer for Nature. 